if indeed equalled, in riches elsewhere-such riches, for example, as the Gothic buildings or the village churches with their painted decorations, to which Sir Charles referred. Since attention was directed recently to the danger which threatens the antiquities of the island, an inspector of antiquities has been appointed; this is only a partial discharge of the responsibility entailed by Britain's occupation of Cyprus since 1878, and its formal status as a colony since 1925, now that the inhabitants have fallen on evil days through the economic depression. On historical and æsthetic grounds, the Cyprus Monuments Fund (6 Pall Mall, London, S.W.1), for which several thousand pounds will be needed, deserves the fullest support.

\section{Elements and Isotopes}

The first Friday evening discourse of the new session at the Royal Institution was delivered on November 2 by Dr. F. W. Aston, who took as his subject "Elements and Isotopes". That a chemical element could consist of isotopes of different atomic mass was first observed by Soddy when working on the products of radioactivity. Proof that this was true of the elements generally could only be obtained by direct atomic analysis. This was achieved by the mass-spectrograph, and with it the search for isotopes has been carried on continuously for the past fifteen years. Wide differences of properties among the elements necessitate very varied methods of obtaining the atomic rays required for the analysis. In some cases the technical difficulties are great; it is only during the last year that satisfactory results have been obtained with the rare earth group. Of the common elements, all but four, palladium, iridium, platinum and gold, have now been analysed and some 247 isotopes identified, a few by less direct optical methods. Elements of odd atomic number appear curiously limited to two isotopes, but elements of even atomic number can have many more, eleven in the case of tin. By means of modern instruments, it is possible to compare the masses of atoms to one part in ten thousand, an accuracy which it is expected to increase in the near future. These isotopic weights are required in order to test theories of nuclear structure, which have recently become of the greatest importance on account of the discovery of transmutation and of artificial production of radioactive isotopes.

\section{Exploration of Nanda Devi}

NANDA Devr, with an altitude of $25,645 \mathrm{ft}$., in the Kumaun Himalayas, is supposed to be the highest mountain entirely within British territory. The area in which it lies is so rugged and unapproachable that even the base of the main peak defied assault until this year, though in 1907 Dr. T. G. Longstaff made an attempt via the Rishiganga gorge. In a letter to the Times of November 2, Mr. H. Ruttledge gives a preliminary account of an expedition to Nanda Devi led by Mr. E. E. Shipton this year. In June, with Mr. Tilman and a few native carriers, Mr. Shipton forced a way up the precipices of the Rishiganga gorge to the source of the river and explored the northern flank of Nanda Devi. Before the monsoon broke, they retreated northward and during July and August explored the Arwa, Bhagat-Kharak, and Satopanth glaciers before returning to their main task. Once more they ascended the Rishiganga gorge, mapped the southern basin of Nanda Devi, climbed a considerable distance up the peak and discovered a way that in the proper season would no doubt lead to the top. Finally, in September they crossed the difficult Sonadunga col and descended to the south. Mr. Shipton is returning to Great Britain next month.

\section{Sixty Years' Progress in Naval Construction}

SrR ARTHuR JoHNs, director of naval construction, for his Andrew Laing lecture to the North-East Coast Institution of Engineers and Shipbuilders on November 2, took for his subject "Progress in Naval Construction". Beginning with a comparison of the Navy in 1874 and 1934 , he dealt in turn with materials, the development of the capital ship and of cruisers, torpedo vessels, submarines, aircraft on warships, model experiments, welding and stability and strength. Nothing perhaps was more striking than the figures he gave regarding tonnage, horse-power and speed. The displacement tonnage of our fighting ships in 1874 was 825,000 as compared with $1,275,000$ of to-day, while the corresponding figures for horsepower are 590,000 and 9,500,000. A cruiser of 1874 had engines of 4,500 horse-power and a speed of 14 knots; a cruiser of to-day develops 72,000 horsepower and has a speed of $32 \frac{1}{2}$ knots. Though Sir Arthur Johns' review was necessarily a cursory one, it was a valuable authoritative review of the main lines of progress and contains references to many of the most interesting vessels ever launched. He paid an eloquent tribute to the work of William Froude, whose theory of a propeller's operation is still the simplest and most representative, and whose method of computing the skin resistance of full-sized ships has stood the severest tests. Regarding the stability of ships, this has been the bugbear of naval architects since the thirteenth and fourteenth centuries, and even after Bouquer had defined the meta-centre and shown how its position was determined, Atwood in a paper to the Royal Society proved to his own satisfaction that the meta-centre was a mere mathematical curiosity, useless to the naval architect. It was the researches of White and John after the capsising of the Captain in 1871 which made a marked advance in our knowledge of the stability of a ship and of the features which improve or adversely affect it.

\section{Coal Mining in Great Britain}

SiR RICHARD Redmayne delivered the presidential address to the Institution of Civil Engineers at the opening meeting of the new session on November 6 . Sir Richard has been for many years associated with coal mining in Great Britain, and it was appropriate that he should discuss aspects of the industry. In tracing its development, he pointed out that the growth of the railway and the application of steam 